\title{
COMPARATIVE STUDIES OF OXIDATIVE ENZYME SYSTEMS IN EPIDERMIS AND FAT BODY OF DIAPAUSING AND NON-DIAPAUSING SILKMOTHS
}

\author{
DAVID G. SHAPPIRIO \\ Department of Zoology, The University of Michigan, 1116 Natural Science Building, \\ Ann Arbor, Michigan 48104, U.S.A.
}

(Received 17 fuly 1973)

\begin{abstract}
The activities of four oxidative enzyme systems, including NADH oxidase, succinate-cytochrome $c$ reductase, NADH-cytochrome $c$ reductase, and cytochrome $c$ oxidase, were compared in mitochondrial-microsomal preparations from wing epidermis and fat body of diapausing Samia cynthia pupae, presumptively non-diapausing $S$. cynthia ricini pupae which were caused to diapause by removal of the brain, and non-diapausing $S$. cynthia ricini during the pupal and pharate adult period. In diapausing pupae the activities of all enzyme systems were low and presented a profile similar to that previously reported for the Cecropia silkmoth. By contrast, in non-diapausing individuals the activities showed substantially higher levels, and an essentially unchanging pattern from just after the larval-pupal ecdysis through most of adult development. These events are functionally correlated with the patterns of biosynthetic activity in diapausing and non-diapausing silkmoths and are discussed in relation to the endocrine control of diapause and development.
\end{abstract}

\section{INTRODUCTION}

Previous studies on the Cecropia silkmoth, Hyalophora cecropia, have shown that the components of the electron transport system undergo a prominent decline and equally striking resynthesis in synchrony with the onset and termination of pupal diapause (Shappirio and Williams, 1957a, b; Shappirio, 1966). This pupal diapause results from endocrine events coupled to the onset and termination of the pupal stage in the insect's life history (Williams, 1946, 1952). Owing to the obligatory character of pupal diapause in $H$. cecropia it has been impossible to discern the extent to which the observed respiratory changes are part of the functional metamorphosis to pupal and adult life, as distinguished from special adaptations for diapause. The validity of this concern is apparent when one considers the cell biology of metamorphosis in lepidopterous insects that do not display pupal diapause. Thus, in a non-diapausing silkmoth, DNA synthesis virtually ceases in epidermal tissue at the time of pupation and resumes shortly thereafter when the animal initiates adult development (KRISHNaKumaraN et al., 1967). And studies on the skipper Calpodes ethlius have shown that dramatic ultrastructural changes, including substantial destruction of mitochondria, are part 
of the transition to pupal life in the fat body of this non-diapausing species (LockE and Collins, 1965, 1968; LARSEN, 1970). Indeed, it has been known for half a century and more that the ' $U$-shaped curve' describing respiratory metabolism in metamorphosing insects is typical of non-diapausing as well as diapausing individuals, though the depth and prolongation of the curve are markedly greater when pupal diapause intervenes (KROGH, 1914; Heller, 1926).

The present study is intended to afford a comparative picture of the behaviour of terminal oxidative enzyme systems in diapausing and non-diapausing silkmoths, during the time period surrounding the pupal stage in the life cycle. For this purpose, the silkmoth Samia cynthia was selected, by virtue of its close relationship to $H$. cecropia on which much previous respiratory data are based, and owing to its extensive recent use for developmental studies in other laboratories (e.g. KrishnakUmaRaN et al., 1967). In the present study, the activity of four oxidative enzyme systems has been examined in non-diapausing $S$. cynthia, in presumptively non-diapausing individuals which were caused to diapause by surgical means, and in naturally diapausing individuals. Attention has been focused on wing epidermis, the object of previous studies with $H$. cecropia. Additional measurements have been carried out on fat body, which has not been the subject of previous studies on respiratory metabolism in silkmoths. A preliminary note of studies on the behaviour of cytochrome $c$ in diapausing and non-diapausing Antheraea pernyi has been published elsewhere (SHAPPIRIO, 1956).

\section{MATERIALS AND METHODS}

\section{Experimental animals}

Samia cynthia, indigenous to southern and eastern Asia, exists in a number of races or subspecies, including forms with an obligatory pupal diapause, a facultative pupal diapause, or no diapause (DaNILEVSkII, 1965). The diapausing pupae used in this study were $S$. cynthia cynthia from the naturalized northeastern United States population, which since its introduction from China a century ago has apparently altered from a double-brooded to a single-brooded status, exhibiting obligatory pupal diapause. The non-diapausing individuals used in this study were $S$. cynthia ricini, native to India but maintained in continuous indoor culture in England; these insects do not exhibit pupal diapause. The biosystematics and life history of S. cynthia have recently been reviewed in detail, with special reference to the North American population (FERGuson, 1972). The nomenclature used in this paper for these two forms of $S$. cynthia coincides with Ferguson's treatment. According to this nomenclature, insects described here as $S$. cynthia cynthia are identical with those in previous physiological studies on $S$. cynthia from North America in which the names $S$. walkeri, S. cynthia walkeri, or Philosamia cynthia were used. S. cynthia ricini has occasionally been termed Philosamia ricini.

Diapausing pupae (S. cynthia cynthia) were collected in New York via commercial sources, and were maintained in the laboratory at $25^{\circ} \mathrm{C}$ for several months during which time none terminated diapause and initiated adult development. Non-diapausing individuals ( $S$. cynthia ricini) were imported from England; just 
after mature larvae had completed feeding, they were shipped by air to Michigan, where they arrived while in the act of cocoon construction. They were henceforth maintained at $25^{\circ} \mathrm{C}$. The larval-pupal ecdysis occurred within a few days thereafter. The absence of pupal diapause was confirmed by the prompt initiation of adult development as signalled by apolysis. Among a sample of several hundred individuals, the time between completion of the larval-pupal ecdysis and retraction of the leg epidermis from pupal cuticle was 2 to 3 days. Subsequent events in adult development also proceeded according to the normal schedule for S. cynthia ricini (SchNEIDERMAN, 1967).

A number of presumptively non-diapausing pupae were caused to diapause by surgical removal of their brains within $18 \mathrm{hr}$ after the larval-pupal ecdysis. Standard surgical procedures were used, the details of which are given elsewhere (Williams, 1946, 1959). The operated pupae were maintained at $25^{\circ} \mathrm{C}$ for several months during which time they were superficially indistinguishable from ordinary diapausing pupae.

\section{Preparative procedures and enzymatic measurements}

Wings and fat body were dissected in ice-cold 0.32 M sucrose solution containing a few crystals of phenylthiourea to inhibit phenoloxidase activity. To provide adequate material, tissue was pooled from several animals at the same stage in development or diapause. A particulate enzymatic fraction was then isolated following homogenization and differential centrifugation according to methods described elsewhere in detail (ShappIRIo and HaRvey, 1965). This fraction includes at least 90 per cent of the mitochondrial material in the initial homogenate, as well as virtually all the microsomal elements containing cytochrome $b_{5}$ and associated components. The following oxidative enzyme systems were assayed spectrophotometrically: NADH oxidase, succinate-cytochrome $c$ reductase, $\mathrm{NADH}$-cytochrome $c$ reductase, and cytochrome $c$ oxidase. Appropriate trials demonstrated that the assay conditions employed by SHAPPIRIO and HARVEY (1965) for $H$. cecropia wing epidermis were also valid for measurements on $S$. cynthia wing and fat body, provided that due attention was paid to the presence of endogenous reducing substance in particulate fractions from fat body. This substance is capable of reducing cytochrome $c$ and potentially interfering with both reductase systems; its influence was minimized by preincubating all components of reductase systems, except for $\mathrm{NADH}$ or succinate, for $3 \mathrm{~min}$ before starting the reaction by addition of the substrate. This eliminated all but a controllable trace of endogenous reducing power without significantly depleting the cytochrome $c$ used as the electron acceptor. The substance did not significantly alter the initial rate of oxidation of cytochrome $c$ or NADH and was therefore ignored in measurements of cytochrome $c$ oxidase and $\mathrm{NADH}$ oxidase activity. The activities of all four oxidative enzyme systems were expressed on a nitrogen basis, using the FolinCiocalteau phenol reagent calibrated against Kjeldahl nitrogen analyses of the particulate fractions isolated from wing and fat body of diapausing and nondiapausing S. cynthia. 


\section{RESULTS}

\section{Wing epidermis from diapausing pupae}

Table 1 records the activity of the four oxidative enzyme systems examined in the wings of diapausing pupae. In the case of normally diapausing pupae ( $S$. cynthia cynthia) the results may be summarized by observing their close similarity to those previously reported for similar preparations from the wings of $H$. cecropia pupae during diapause (Shappirio and HarveY, 1965). For convenience, data for $H$. cecropia have been included in Table 1 . The aforementioned similarity includes the fact that NO activity is either undetectable or only barely detectable, while $\mathrm{SCR}, \mathrm{NCR}$, and $\mathrm{CO}$ activities remain detectable though at relatively low levels compared to the same systems in the absence of diapause. It should be noted that despite the general similarity in oxidative enzyme profile between $S$. cynthia and $H$. cecropia, there appear to be certain interspecific differences in the actual numerical levels of activity, especially for NCR and CO which appear somewhat higher in $S$. cynthia cynthia than $H$. cecropia.

A generally similar picture prevails in preparations from wings of $S$. cynthia ricini in which diapause was evoked by removal of the brain during the first day after the larval-pupal ecdysis. As shown in Table 1, NO activity was again undetectable or barely detectable, while the activities of the other three enzyme systems were rather low. Despite seeming differences detected between the two

TABle 1-OXIDATIVE ENZYME SYSTEMS IN WING EPIDERMIS FROM DIAPAUSING PUPAE

\begin{tabular}{lccccc}
\hline \multicolumn{1}{c}{ Animals } & NO & SCR & NCR & CO & No. \\
\hline S. cynthia cynthia (assays & $<3$ & 33 & 140 & 520 & 15 \\
3 months after larval-pupal & 15 & 21 & 120 & 470 & 15 \\
ecdysis) & $<4$ & 28 & 150 & 530 & 14 \\
Mean \pm average deviation & $7 \cdot 3 \pm 5$ & $27 \pm 4$ & $140 \pm 10$ & $510 \pm 23$ & \\
S. cynthia ricini (assays & 13 & 45 & 130 & 580 & 6 \\
3-4 months after larval-pupal & $<13$ & 34 & 84 & 260 & 6 \\
ecdysis and brain removal) & $<8$ & 48 & 50 & 220 & 6 \\
Mean \pm average deviation & $11 \pm 2$ & $42 \pm 6$ & $88 \pm 28$ & $350 \pm 150$ & \\
H. cecropia (assays 2-3 months & $4 \cdot 8 \pm 2$ & $21 \pm 6$ & $85 \pm 19$ & $230 \pm 77$ & \\
after pupation; data from & & & & & \\
SHAPPIRIO and HaRVEY, 1965) & & & & & \\
\hline
\end{tabular}

NO, NADH oxidase (units of activity, nmoles $\mathrm{NADH}$ oxidized $\times \mathrm{mg} \mathrm{N}^{-1} \times$ $\min ^{-1}$ ). SCR, NCR, Succinate, NADH cytochrome $c$ reductases (units, nmoles cytochrome $c$ reduced $\times \mathrm{mg} \mathrm{N}^{-1} \times \min ^{-1}$ ). $\mathrm{CO}$, Cytochrome $c$ oxidase (units, nmoles cytochrome $c$ oxidized $\times \mathrm{mg} \mathrm{N}^{-1} \times \mathrm{min}^{-1}$ ). Activities measured on mitochondrial-microsomal fraction derived from pooled wings of number of animals indicated in right-hand column. When NADH oxidase was below a detectable level, the table records 'less than' the activity which would have been minimally detectable under the experimental conditions; in calculating mean NO activity this minimal figure was included. 
races of $S$. cynthia studied, the activities of all oxidative enzyme systems encountered in diapausing pupae are substantially lower than those observed in the absence of diapause, as will be evident from the paragraph that follows.

\section{Wing epidermis from non-diapausing individuals}

In S.cynthia ricini the duration of the pupal stage, as calculated from completion of larval-pupal ecdysis to the first visible sign of adult development, is only 2 to 3 days, by contrast with diapausing individuals in which the pupal stage occupies 8 months or more. Since pupal life in non-diapausing individuals leads so directly into adult development, enzymatic data on wings of these insects has been presented in Table 2 as a continuous series from 2 to $3 \mathrm{hr}$ to 13 days after the larval-pupal ecdysis. At the latter time adult morphogenesis is nearly complete and only about 3 days remain before eclosion of the fully formed adult moth.

The first point that emerges from the data in Table 2 is that despite substantial variation from one preparation to the next, the levels of enzymatic activity for all four enzyme systems are almost invariably substantially higher than those for the same enzyme systems in preparations from wings of diapausing $S$.cynthia (Table 1 ). This conclusion applies both for naturally diapausing pupae and for those in which diapause was surgically imposed.

TABle 2-OXIDATIVE ENZYME SYSTEMS IN WING EPIDERMIS FROM PUPAE AND PHARATE ADULTS OF NON-DIAPAUSING $S$. cynthia ricini

\begin{tabular}{ccccrr}
\hline $\begin{array}{c}\text { Animals (time after larval-pupal } \\
\text { ecdysis, hr) }\end{array}$ & NO & SCR & NCR & CO & No. \\
\hline $2-3$ & 23 & 160 & 430 & 840 & 5 \\
13 & 50 & 200 & 310 & 1400 & 4 \\
18 & 42 & 150 & 270 & 1500 & 2 \\
25 & 24 & 140 & 260 & 1200 & 4 \\
36 & 16 & 130 & 210 & 1100 & 3 \\
48 & 24 & 210 & 400 & 1200 & 11 \\
50 & 16 & 110 & 240 & 950 & 2 \\
52 & -100 & 150 & 1400 & 3 \\
67 & 45 & 110 & 170 & 1100 & 8 \\
75 & 13 & 100 & 120 & 1000 & 6 \\
81 & 15 & 140 & 290 & 1400 & 5 \\
96 & 22 & 110 & 230 & 840 & 6 \\
108 & 26 & 300 & 380 & 1500 & 6 \\
$($ days) & & & & & \\
8 & 10 & 68 & 84 & 740 & 3 \\
9 & 27 & 150 & 190 & 1100 & 4 \\
11 & 35 & 330 & 350 & 1300 & 6 \\
13 & 16 & 120 & 150 & 650 & 6 \\
13 & 15 & 200 & 320 & 1000 & 5 \\
\hline
\end{tabular}

Abbreviations and units of measurement for each enzyme system as in Table 1. 'Number' as in Table 1. Blank space for NO at $52 \mathrm{hr}$ signifies missing datum. 
Table 2 also reveals no clearly discernible change in the levels of enzyme activity, over and above the large but customary variation in this type of preparation, during the pupal and pharate adult portions of the life history. The only possible qualification to this conclusion is an apparent slight clustering of several higher values of $\mathrm{NO}$ activity during the first day of pupal life. Since measurements of NO activity are inherently subject to greater error than those of the other systems, and since the change in activity, even if real, would be rather slight, this possibility was not examined in further detail. It is of interest and importance, however, to note that while several of the lower numerical values for NO activity (recorded in Table 2 on a nitrogen basis) approach levels in wings from diapausing pupae (Table 1 ), there was invariably a readily detectable change in absorbance in preparations from non-diapausing individuals while in corresponding preparations from diapausing pupae any change was only marginally detectable on an absolute basis.

\section{Fat body}

Table 3 records the results of analyses on fat body of S. cynthia ricini, including non-diapausing individuals and pupae in which diapause was surgically imposed. Since NADH oxidase activity was invariably below a detectable level in fat body (minimum detectable activity less than $1 \mathrm{nmole} \mathrm{NADH}$ oxidized $\times \mathrm{mg} \mathrm{N}^{-1} \times$ $\min ^{-1}$ ), data for this enzyme system were excluded from Table 3. The three other systems covered in Table 3 show substantially lower activities when corresponding stages in diapause and development are compared to wing epidermis. Since the activities are expressed on a nitrogen basis, the lower values may result, in part, from the presence in the particulate fraction of protein granules characteristic of this tissue; but inasmuch as very large quantities of tissue were required to prepare a particulate fraction comparable to that of epidermis, the lower activities probably also result from intrinsically lower levels of oxidative enzyme systems in fat body cells, as compared to epidermis.

Apart from the lower levels of activity, it is apparent from Table 3 that the three detectable enzyme systems fail to show substantial change during the pupal and pharate adult period in non-diapausing individuals. The levels of these three systems are lower in the case of diapausing pupae, when compared with the nondiapausing animals. However, the differences here are less striking than for wing epidermis (Tables 1, 2).

During the course of the pupal-adult transition, it becomes difficult to dissect the fat body owing to its fragility and mushy texture. This is already apparent during the second day after the larval-pupal ecdysis and is a consequence of changes in intercellular cohesion (KrishNaKUMARAN et al., 1967; WaLTERS, 1969). It was of interest in the present study that late in adult development, at which time the fat body has recovered its consistency, the levels in oxidative activity continued at essentially unchanging levels, supporting the view (KrishNaKUMARAN et al., 1967) that fat body cells persist throughout metamorphosis, rather than undergo degeneration as reported by IsHIZAKr (1965). 
TABle 3-OxIdative ENZYMe SYSTEMS IN FAT BOdY of S. cynthia ricini

\begin{tabular}{lrrr}
\hline \multicolumn{1}{c}{ Animals } & SCR & NCR & CO \\
\hline Non-diapausing (time after pupation, hr) & & & \\
$2-3$ & $7 \cdot 9$ & - & 110 \\
13 & $8 \cdot 4$ & $8 \cdot 4$ & 130 \\
18 & $11 \cdot 0$ & $15 \cdot 0$ & 110 \\
25 & $8 \cdot 9$ & $19 \cdot 0$ & 89 \\
36 & $14 \cdot 0$ & $14 \cdot 0$ & 130 \\
48 & - & $36 \cdot 0$ & 220 \\
50 & $16 \cdot 0$ & $22 \cdot 0$ & 110 \\
52 & $5 \cdot 8$ & $5 \cdot 8$ & 95 \\
67 & $5 \cdot 3$ & $11 \cdot 0$ & 95 \\
75 & $10 \cdot 0$ & $15 \cdot 0$ & 240 \\
81 & $14 \cdot 0$ & $37 \cdot 0$ & 210 \\
96 & $24 \cdot 0$ & $63 \cdot 0$ & 220 \\
108 & $27 \cdot 0$ & $37 \cdot 0$ & 190 \\
(days) & & & \\
9 & $6 \cdot 8$ & $14 \cdot 0$ & 84 \\
11 & $14 \cdot 0$ & $32 \cdot 0$ & 74 \\
13 & $39 \cdot 0$ & $43 \cdot 0$ & 190 \\
Diapausing (3-4 months after pupation and brain removal) & $4 \cdot 7$ & $13 \cdot 0$ & 79 \\
& $2 \cdot 1$ & $15 \cdot 0$ & 79 \\
& $4 \cdot 7$ & $27 \cdot 0$ & 84 \\
\hline
\end{tabular}

Abbreviations and units of measurement for each enzyme system as in Table 1. Each horizontal row of figures represents activity in mitochondrial-microsomal fraction derived from about $1.5 \mathrm{~g}$ fresh weight of fat body isolated from 2 to 3 animals at the same stage.

\section{DISCUSSION}

Previous quantitative studies on oxidative enzyme systems in relation to pupal diapause have been limited to the wing epidermis of $H$. cecropia (SHAPPIRIO and Harvey, 1965; Shappirio and Williams, 1967). These studies have drawn attention to the very low levels of enzyme activity that prevail during diapause, paralleling the attenuated oxygen consumption at this time (ScHNEIDERMAN and Williams, 1953). The results of the present study clearly show that a similar enzymatic state of affairs prevails in the wings of diapausing $S$. cynthia. Together with essentially similar findings on wings of a third silkmoth species, Antheraea pernyi (ShappIRIo, 1974), the present findings permit the conclusion that this enzymatic profile is a general characteristic in wing, and by inference other epidermal tissue, of diapausing silkmoth pupae. The present study also extends the same conclusion to the fat body of diapausing $S$. cynthia pupae. This conclusion is in accord with unpublished measurements on fat body of diapausing $H$. cecropia, and is in keeping with qualitative spectroscopic observations which showed essentially parallel behaviour of cytochromes in wing and fat body during diapause 
and development (Shappirio and Williams, 1957a). However, the quantitative changes for fat body appear to be of lesser magnitude than for wing epidermis.

According to current interpretation, the finding of low oxidative activity in diapausing silkmoth pupae is hardly surprising in view of other biochemical characteristics that accompany the developmental arrest of these insects. Among the most noteworthy of these characteristics are low levels of macromolecular biosynthesis. In the case of wing and fat body of diapausing $S$. cynthia this involves low or undetectable rates of incorporation of radioactively labelled precursors into protein (Stevenson and WyatT, 1962), into RNA (BerRY et al., 1967), and into DNA (KRISHNAKUmaran et al., 1967). The corresponding situation in other diapausing silkmoths is reviewed by WYATT (1972). The integrated adjustment that attunes respiratory enzyme levels to endergonic demand, which represents an important adaptation of the diapausing state, is achieved by the pupa via mechanisms which remain essentially unknown despite speculation (SHAPPIRIo and HARveY, 1965) and emphasizes the potential which these insects provide for the understanding of molecular regulatory mechanisms in eukaryotic cells.

By contrast with the situation in wing and fat body of diapausing individuals, let us consider the behaviour of oxidative enzyme systems in the same tissues of non-diapausing individuals. As described under Results, the wing and fat body show relatively higher levels of activity, and no clearly discernible change in levels from the outset of pupal life through the initiation and major portion of adult development. Inasmuch as non-diapausing pupae continue many biosynthetic activities during pupal life (KrishnaKUMARAN et al., 1967) this observation emphasizes the functional correlation between respiratory and biosynthetic activity discussed in the preceding paragraph, and strongly implies that in diapausing individuals, the respiratory and enzymatic decline at the outset of pupal life (Schneiderman and Williams, 1953; Shappirio and Williams, 1957a, b) is to be regarded as part of the adjustment for diapause and not simply a general feature of metamorphosis to the pupal stage in the life cycle. However, a possibility remains that even non-diapausing silkmoths show functionally related respiratory alterations toward pupal life, in view of the fact that mitochondrial and other changes in Calpodes ethlius are consummated during the pharate pupal period in advance of ecdysis (Locke and Collins, 1965, 1968), whereas the present observations were commenced only at the outset of pupal life.

The present findings merit consideration in relation to the endocrine mechanism controlling diapause and development. Pupal diapause results from the functional failure of neuroendocrine elements in the brain and corpora cardiaca, which thereupon leads to secretory inactivity of the prothoracic glands; by contrast, in non-diapausing individuals the brain either continues its output after the pupa is formed, or following a brief pause renews its activity (Williams, 1952). This sequence of events operates in $S$. cynthia ricini as demonstrated by the fact that brains removed within the first day after pupation, and implanted into brainless 'dauer-pupae' of $S$. cynthia ricini, cause the latter to initiate adult development in about 7 to 10 days. 
During and just after the larval-pupal transformation, the hormonal milieu evidently favours the continuation of intensive metabolic activity including the 'telescoping' of certain biosynthetic events which in diapausing individuals would be deferred until adult development (KRIShNakumaran et al., 1967). The metabolism is apparently underwritten by a maintenance of the insect's oxidative machinery. By contrast, the latter declines in dauer-pupae of $S$. cynthia ricini, and in terms of oxidative enzyme activity such individuals are essentially indistinguishable from normal diapausing pupae (S. cynthia cynthia). This picture of respiratory enzymes conforms precisely to that furnished by studies of biosynthetic activity. As noted above, the question of mechanism, i.e. how the various metabolic activities become attenuated in the transition to diapause, and later enhanced in response to injury or prothoracic gland hormone, remains a central problem in insect developmental endocrinology (review by WYATT, 1972).

Acknowledgements-I gratefully acknowledge skilful assistance from William D. BUTtERFIELD in some of the experiments reported here, and also thank BRIAN GARDINER for rearing Ricini larvae. This investigation was supported, in part, by Public Health Service Research Grant No. GM-06101 and funds from the Institute of Science and Technology of the University of Michigan.

\section{REFERENCES}

Berry S. J., Krishnakumaran A., Oberlander H., and Schneiderman H. A. (1967) Effects of hormones and injury on RNA synthesis in Saturniid moths. F. Insect Physiol. 13, 1511-1537.

Danilevskir A. S. (1965) Photoperiodism and Seasonal Development of Insects. Oliver \& Boyd, Edinburgh.

Ferguson D. C. (1972) Saturniidae (Part). In The Moths of America North of Mexico, Fascicle 20.2B (Ed. by Dominick R. B., Edwards C. R., Ferguson D. C., Franclemont J. G., Hodges R. W., and Munroe E. G.). Curwen, London.

HeLler J. (1926) Chemische Untersuchungen über die Metamorphose der Insekten-III. Mitteilung: über die 'subitane' und 'latente' Entwicklung. Biochem. $Z$. 169, 208-234.

IsHIZAKI H. (1965) Electron microscopic study of changes in the subcellular organization during metamorphosis of the fat body cell of Philosamia cynthia ricini (Lepidoptera). Y. Insect Physiol. 11, 845-855.

Krishnakumaran A., Berry S. J., Oberlander H., and Schneiderman H. A. (1967) Nucleic acid synthesis during insect development-II. Control of DNA synthesis in the Cecropia silkworm and other Saturniid moths. F. Insect Physiol. 13, 1-57.

KroGr A. (1914) On the rate of development and $\mathrm{CO}_{2}$ production of chrysalides of Tenebrio molitor at different temperatures. Z. allg. Physiol. 17, 178-190.

LARSEN W. J. (1970) Genesis of mitochondria in insect fat body. F. Cell Biol, 47, 373-383.

LOCKE M. and Collins J. V. (1965) The structure and formation of protein granules in the fat body of an insect. F. Cell Biol. 26, 857-884.

Locke M. and Collins J. V. (1968) Protein uptake into multivesicular bodies and storage granules in the fat body of an insect. F. Cell Biol. 36, 453-483.

Schneiderman H. A. (1967) Rearing of Samia cynthia ricini. In Methods in Developmental Biology (Ed. by Wilt F. H. and Wessells N. K.), pp. 180-181. Thomas Y. Crowell, New York.

Schneiderman H. A. and Williams C. M. (1953) The physiology of insect diapause-VII. The respiratory metabolism of the Cecropia silkworm during diapause and development. Biol. Bull., Woods Hole 105, 320-334. 
Shappirio D. G. (1956) Hormonal control of cytochrome $c$ synthesis in silkworms. Proc. 20th Physiol. Congr. Brussels.

Shappirio D. G. (1966) Pyridine nucleotide levels in silkmoth fat body during the onset, maintenance, and termination of pupal diapause. F. Cell Biol. 31, 104A.

SHAPPIRIo D. G. (1974) Respiratory enzyme systems in the wing epidermis of metamorphosing Antheraea pernyi. In preparation.

Shappirio D. G. and Harvey W. R. (1965) The injury metabolism of the Cecropia silkworm-II. Injury-induced alterations in oxidative enzyme systems and respiratory metabolism of the pupal wing epidermis. F. Insect Physiol. 11, 305-327.

Shappirio D. G. and Williams C. M. (1957a) The cytochrome system of the Cecropia silkworm-I. Spectroscopic studies of individual tissues. Proc. R. Soc. (B) 147, 218 232.

Shappirio D. G. and Williams C. M. (1957b) The cytochrome system of the Cecropia silkworm-II. Spectrophotometric studies of oxidative enzyme systems in the wing epithelium. Proc. R. Soc. (B) 147, 233-246.

Stevenson E. and Wyatt G. R. (1962) The metabolism of silkmoth tissues. Incorporation of leucine into protein. Archs Biochem. Biophys. 99, 65-71.

WALTERS D. R. (1969) Reaggregation of insect cells in vitro-I. Adhesive properties of disassociated fat-body cells from developing Saturniid moths. Biol. Bull., Woods Hole 137, 217-227.

Williams C. M. (1946) Physiology of insect diapause: The role of the brain in the production and termination of pupal dormancy in the giant silkworm Platysamia cecropia. Biol. Bull., Woods Hole 90, 234-243.

Williams C. M. (1952) Physiology of insect diapause-IV. The brain and prothoracic glands as an endocrine system in the Cecropia silkworm. Biol. Bull., Woods Hole 103, 120-138.

Williams C. M. (1959) The juvenile hormone-I. Endocrine activity of corpora allata of the adult Cecropia silkworm. Biol. Bull., Woods Hole 116, 323-335.

WYatT G. R. (1972) Insect hormones. In Biochemical Actions of Hormones (Ed. by LiTwaCK G.) 2, 385-490. Academic Press, New York. 